DOI: 11

\title{
Undermined Part of Thyroid in Human Health
}

\section{Deepti B*, Srinivasa Babu P, Harendra Kumar D, Niranjan Kumar M, Prasad S and Rahmatulla SD}

Department of Pharmacology, Vignan Pharmacy College, Vadlamudi, Guntur, Andhra Pradesh, India

*Corresponding author: Deepti B, Department of Pharmacology, Vignan Pharmacy College, Vadlamudi, Guntur, Andhra Pradesh, India, Tel: 09885250281; E-mail: deepubandarupalli@gmail.com

Rec date: Sep 6, 2016; Acc date: Sep 19, 2016; Pub date: Sep 26, 2016

Copyright: 2016 Deepthi B, et al. This is an open-access article distributed under the terms of the Creative Commons Attribution License, which permits unrestricted use, distribution, and reproduction in any medium, provided the original author and source are credited.

Citation: Deepti B, Srinivasa Babu P, Harendra Kumar D, et al. Undermined part of thyroid in human health. J In Silico In Vitro Pharmacol. 2016, $2: 3$

\section{Abstract}

Thyroid gland is said to be one of the largest gland in our body. The hormones secreted by thyroid gland are namely T3 (liothyronine) and T4 (levothyroxine). The abnormalities (either increase or decrease) in these hormone levels may leads to various complications. The increased level of thyroid hormones in the body is called hyperthyroidism, whereas decreased levels of thyroid hormones in the body is called hypothyroidism or underactive thyroid. The major complications of hyperthyroidism are Graves' disease, Thyroiditis, Thyroid nodule etc., and major complications of hypothyroidism are Goiter, Heart problems, Mental health issues, Infertility, Myxedema, Birth defects etc.

Keywords Thyroid gland; Liothyronine; Levothyroxine; Hyperthyroidism; Hypothyroidism; Goiter; Graves' disease

\section{Introduction}

Thyroid is one of the largest endocrine gland in the body which is present in the neck in front of trachea and larynx at the level of $5^{\text {th }}, 6^{\text {th }}, 7^{\text {th }}$, cervical and $1^{\text {st }}$ thoracic vertebrae [1]. This highly vascularised gland weighs about $25 \mathrm{~g}$ and it is surrounded by fibrous capsule. The main function of this butterfly shaped gland is to synthesize, store and release thyroid hormones into our body [2].

And these hormones are namely T3 (liothyronine) and T4 (levothyroxine), affect almost every cell in your body, and help control your body's functions. The hormone synthesis and secretion is regulated by thyroid stimulating hormone (TSH) from anterior pituitary. The rising level of TSH promotes iodide trapping by the gland, which leads to increase in thyroid hormone synthesis. Both T4 and T3 are produced within the follicular cells of the thyroid. The ratio of T3:T4 secreted by the gland is approximately 1:10 (Figure 1).

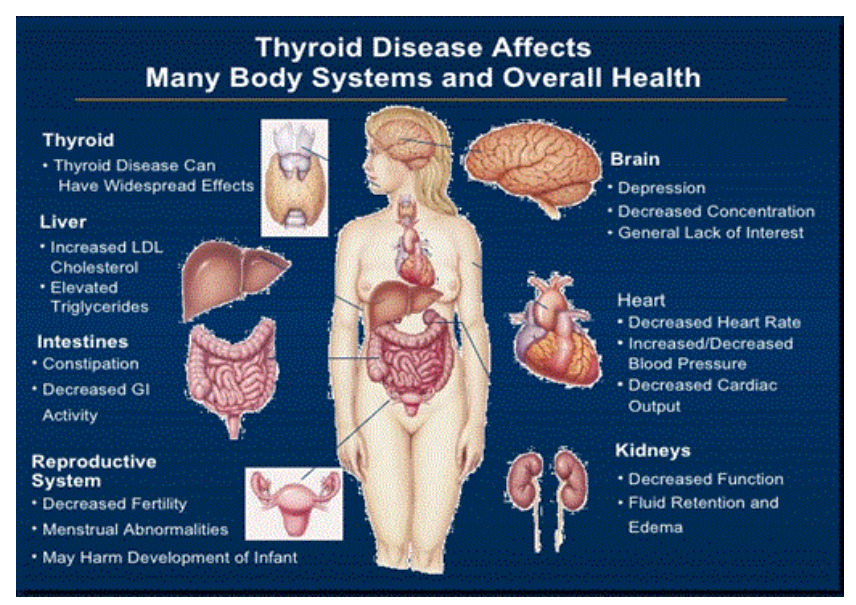

Figure 1: Effect of thyroid dysfunction on various systems.

\section{Causes for Thyroid Abnormalities}

\section{Hypothyroidism}

\section{Primary}

- Autoimmune hypothyroidism: Hashimoto's thyroiditis, atrophic thyroiditis.

- Drugs: lodine excess (including iodine-containing contrast media and amiodarone).

- Congenital hypothyroidism: Absent or ectopic thyroid gland, dyshormonogenesis.

- TSH-R mutation [3] iodine deficiency (Figure 2). 


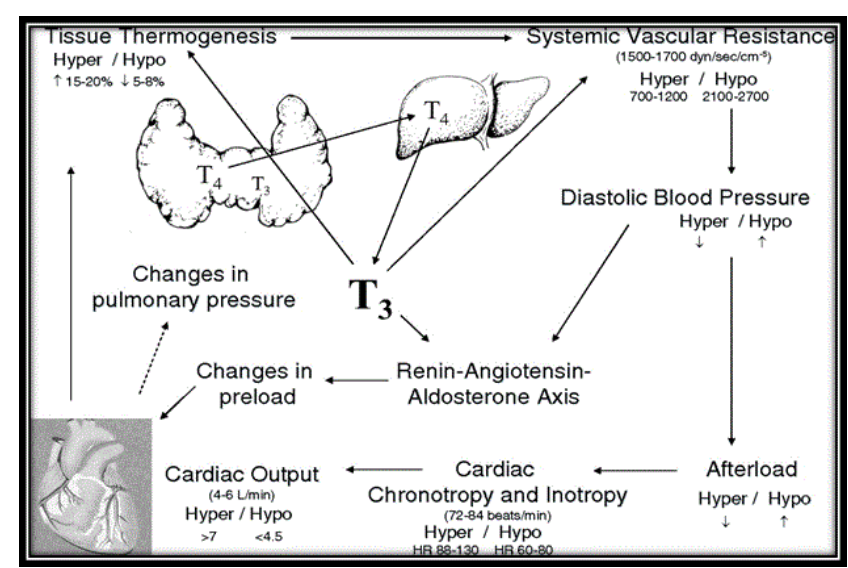

Figure 2: Effect of hypothyroidism on cardiovascular system.

\section{Secondary}

- Hypopituitarism: Tumors, pituitary surgery or irradiation, infiltrative disorders, Sheehan's syndrome, trauma, genetic forms of combined pituitary hormonedeficiencies.

- Isolated TSH deficiency or inactivity.

\section{Bexarotene treatment}

- Hypothalamic disease: Tumors, trauma, infiltrative disorders, idiopathic.

\section{Thyrotoxicosis (Hyperthyroidism)}

\section{Primary hyperthyroidism}

- Graves' disease.

- Toxic multinodular goiter.

- Toxic adenoma.

- Activating mutation of the TSH receptor.

- Drugs: lodine excess (Jod-Basedow phenomenon).

\section{Secondary hyperthyroidism}

- TSH-secreting pituitary adenoma.

- Thyroid hormone resistance syndrome: Occasional patients may havefeatures of thyrotoxicosis.

- Chorionic gonadotropin-secreting tumorsa.

- Gestational thyrotoxicosisa.

\section{Hperthyroidism}

The abnormal condition of the thyroid gland in which it secretes the excess amount of thyroid hormone than the required. This excess amount of thyroid hormones may leads to various complications on various organ systems and they are described below:

\section{Effect of thyrotoxicosis on cardiovascular system}

Generally for any physician the first alarming signs of hyperthyroidism are cardiovascular signs and complications, where they can be direct or indirect. The most frequent signs are palpitations and exercise intolerance. The most common and fearful arrhythmic complication of hyperthyroidism is atrial fibrillation which is about $10-15 \%$ of all hyperthyroid patients [4].

Probably because of older age, the patients with Graves' diseasehave lower cardiovascular riskthanpatients with toxic multinodular goiter. valvular involvement, cardiomyopathy and pulmonary arterial hypertension are also observed in patients with Gravesdisease [5]. Effects of thyroid hormones on the heart may be grouped as molecular or cellular mechanisms and hemodynamic effects. On the other hand, thyroid hormones have 2 types of effects on every tissue; genomic effects which occur more slowly, and non-genomic effects.

\section{Effect of thyrotoxicosis on nervous system}

Hyperthyroidism can be related with muscular disorders such as acute and chronic thyrotoxicosismyopathies, exophthalmia, myasthenia gravis, and periodic paralysis. Pre monitoring symptoms such as aches, cramps and stiffness can be seen. The typical motor involvement in Thyrotoxicosis induced periodic paralysis begins from the lower limbs and ascends to the upper limbs. The muscles affected may be asymmetrical. The severity of attacks ranges from mild weakness to severe paralysis. Clinical improvement starts from the most recently affected muscles. Sensory function is not affected and deterioration of mental functions has never been seen [6].

\section{Psychosis}

Thyrotoxicosis induced psychotic reactions are extremely rare and it was reported in $1 \%$ of cases and most patients who develop psychosis have been previously diagnosed with mania and/or delirium [7]. The occurrence of psychosis depends on the severity and duration of thyroid disease and the underlying predisposition of the individual to psychiatric instability. Hyperthyroidism can exacerbate seizures and paroxysmal EEG abnormalities in patients with a diagnosis of epilepsy or focal/generalized seizures only during thyrotoxicosis inpatients without established epilepsy [8].

\section{Effect of thyrotoxicosis on reproductive system}

Abnormalities in thyroid hormone levels will effect MRS more when compared with FRS. Thyrotoxicosis induces abnormalities in sperm motility, whereas hypothyroidism causes abnormalities in sperm morphology.

They are reversible when the thyroid hormones are in normal range. In females thyrotoxicosis causes hypomenorrhea and polymenorrhea, whereas hypothyroidism causes oligomenorrhea. Thyroid dysfunction also reduces the fertility.

\section{Effect of thyrotoxicosis on digestive system}

Both thyrotoxicosis and hypothyroidism have similar digestive manifestations but the mechanisms are different in each system [9].

The liver is the most effected organ in both the condition. Sometimes digestive diseases may also associated with 
autoimmune thyroid processes, like Hashimoto's thyroiditis and Grave's disease.

\section{Effect of thyrotoxicosis on pancreas}

Thyroid hormones affect glucose metabolism via several mechanisms. Hyperthyroidism has long been recognized to promote hyperglycemia. During hyperthyroidism, the half-life of insulin is reduced most likely secondary to an increased rate of degradation and an enhanced release of biologically inactive insulin precursors. In a study by Bech et al. increased proinsulin levels were observed in response to a meal in people with untreated Graves' disease [10].

\section{Effect of thyrotoxicosis on bones}

Thyrotoxicosis is one of the major risk factor for osteoporosis. It is also proved in both in vitro and in vivo studies that thyroid hormone levels have effects on bone. Therefore treating this thyrotoxicosis leads to reversal of bone loss and metabolic alterations, and decreases the fracture risk.

\section{Hypothyroidism}

Underactive thyroid or Hypothyroidism is the condition in which the thyroid gland does not secretes sufficient amounts of thyroid hormones. This hypothyroidism condition shows different complications on different systems and they are described below.

\section{Effects on cardiovascular system}

The cardiovascular system manifestations of hypothyroidism as a result of decreased action of thyroid hormone on the both heart and the peripheral circulation. The patients who have hypothyroid impaired cardiac contractility with decreased cardiac output, increased peripheral vascular resistance and decreased blood volume, and peripheral oxygen consumption. Cardiac parameters indicate depressed myocardial function in hypothyroid patients. In Hypothyroid patients heart rate decreases slightly, and cardiac contractility is affected with systolic and diastolic function. Cardiac cycle is also affected by hypothyroidism. In case of severe hypothyroidism patients there decrease of $60 \%$ in the left ventricular ejection time and prolongation of the pre-ejection time by $40 \%$. These changes particularly important for the patients with surgery and some degree of heart failure patients. The thyroid hormone hormone also activities of several enzymes involved in regulation of calcium fluxes in the heart. The alterations seen in the cytoplasmic reticulum for calcium handling and a depression of the myosin ATP ase activity contribute to decrease in myocardial contractility [11]. Many of the hemodynamic changes are due to the hypothyroidism suggest a decrease in adrenergic tone but this is not caused by decreased levels of catecholamine. A complex interaction between the thyroidhormone and catecholamines seems to exist.

\section{Effects on respiratory system}

In hypothyroid patients there are several abnormalities are observed in the respiratory functions. Such as a low breathing capacity and low diffusing capacity for carbon monoxide.
Hypercapneic ventilatory drive is also severely impaired. The etiology of impaired respiratory function is induced by altered gene expression in the gene products of the muscle cellsand dysfunction of the phrenic nerve. The presence of hypothyroidism with muscular dysfunction together with increase in the size of the muscles are called Hoffmann's syndrome. Hypothyroidism is also associated with the sleep apnea and all its complications, which can adversely influence surgical outcome [12]. In animal models, improvement of synthesis and improved clinical outcomes has been reported with the T3 therapy.

\section{Effects on renal function, electrolyte metabolism and plasma volume}

Hypothyroidism has a multiple effects on renal functions like increased systemic vascular resistance, increased antidiuretic hormone $(A D H)$, decreased atrial natriuretic factor (ANF), decreased renal perfusion, and decreased activity of the rennin-angiotensin-aldosterone system. In hypothyroid patients other renal alterations should be observed they are inability to produce concentrated or diluted urine, impaired urinary acidification and decreased glomerular filtration rate $[13,14]$. These abnormalities in the glomerular hemodynamics at the single nephron level are characterized by the hypoperfusion and decreased permeability of the glomerular capillaries, resulting the decreasing of glomerular filtration rate. These hemodynamic changes the presence of vasoconstrictor compounds influencing renal function. Recent findings suggest that the association of hypothyroidism with changes in ATP metabolism play a greaterrole in the pathophysiological mechanisms involved in the abnormalities of renal function (Figure 3).

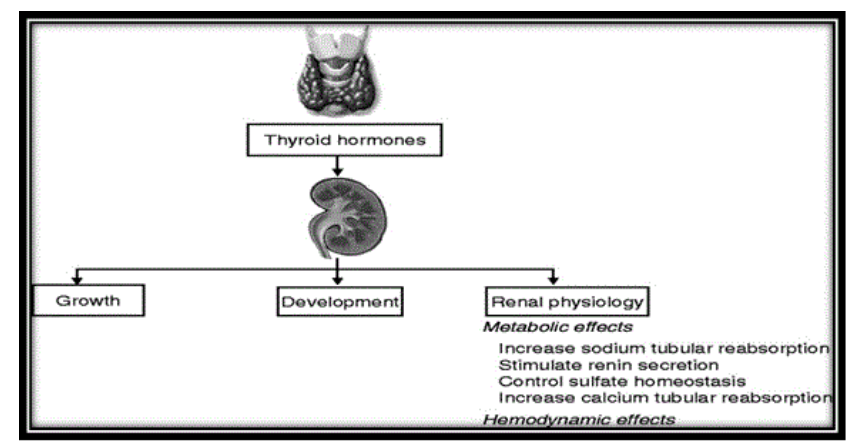

Figure 3: Effect of hypothyroidism on renal system.

\section{Effects on hemopoietic and coagulation systems}

Hypothyroidism is frequently associated with anemia and few changes in other blood cellular elements. In hypothyroid patients erythropoiesis is reduced owing to low metabolic rate, decreased oxygen consumption and decrease in erythropoietin levels. In hypothyroid patients

anemia is reported in about $25 \%$ to $50 \%$, and more often encountered in children. The anemia is generally normochromic, normocytic and these patients have normal iron, with a hypo cellular bone marrow and normal red cell differentiation [15]. Hypothyroidism is also effects on 
coagulation cascade in during a surgical or dental procedure. In hypothyroidism patients is reported a decrease in plasma factor VIII concentration along with prolonged partial thromboplastin time. Acquired von Willebrand's disease is also seen in association with hypothyroidism.

\section{Goiter}

The thyroid hormone levels are too low; the pituitary gland sends signals to thyroid to make more thyroid hormone. The thyroid gland produces more thyroid hormone and leads to a goiter. It results in decreased swallowing and breathing (Figure 4).

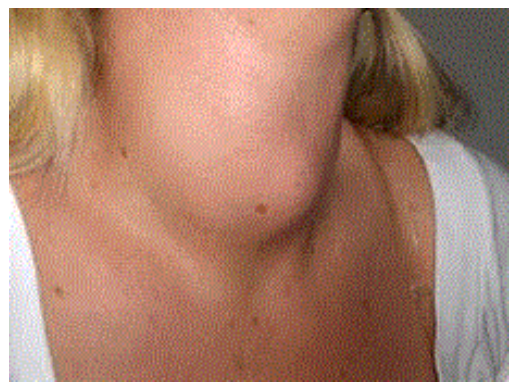

Figure 4: Simple goiter.

\section{Pregnancy complications}

Thyroid hormones deficiency during pregnancy may increase the risk of a miscarriage or other complications like preeclampsia or preterm birth.

\section{Levels of Prevention of Thyroid Disorders}

\section{Primordial prevention}

- Educate the family regarding lifestyle measures, good food habits, positive attitude to be inculcated in young child [16].

- Regular exercise.

- Desirable BMI.

- Health promotive measures and attitude.

- Identifications and elimination of exciting or precipitating factors, if any.

\section{Primary prevention}

- Early diagnosis and treatment.

- Reinforce primary and preventive measures.

- Identifications and elimination of exciting or precipitating factors, if any.

\section{Secondary prevention}

- Aggressive reinforcement of:

- Primary and secondary risk intervention.

- Secondary prevention: lipid profile within normal limits.

- Aggressive and effective control of disease.

\section{Tertiary prevention}

1. Disability limitation.
2. Rehabilitation.

\section{Remedies for avoiding thyroid abnormalities}

- Increase the intake of vitamin A.

- Increase your physical activity.

- Maintain in take of iodine.

- Avoid consumption of high calorie food.

- Avoid any kind of stress.

- Have some walnuts, fruits, vegetables, marine phytoplankton, etc.

\section{Conclusion}

Thyroid disorders are mainly seen when there is too much or too less release of thyroid hormones. The untreated hyperactive or underactive thyroid will results in a wide range of health complications. In order to avoid these complications proper treatment should be taken as soon as possible.

\section{References}

Walker R, Whittlesea C (2012) Clinical pharmacy and therapeutics (5th edn.) Elsevier Publications.

Ross, Wilson (2012) Anatomy and Physiology in health and illness (11th edn.) Elsevier publications.

Petersen P, Hansen JM (1988) Stroke in Thyrotoxicosis with atrial fibrillation. NCBI 19: 15-18.

4. Kasper DL, Harrisons TR (2012) Disorders of the Thyroid Gland:Causes of Hypothyroidism and causes of Thyrotoxicosis (19th edn.) Harrisons Principles of Internal Medicine 405: 2289-2293.

5. Biondi B, Kahaly GJ (2010) Cardiovascular involvement in patients with different causes of hyperthyroidism. Nat Rev Endocrinol 6: 431-443.

6. Tinker TD, Vannatta JB (1987) Thyrotoxic hypokalemic periodic paralysis: report of fourcases and review of the literature. J Okla State Med Assoc 80: 11-15.

7. Gagliardi JP, Clary GL (2002) Treatment of Thyrotoxicosis Induced Psychosis. Psychopharmacol Bull 36: 7-13.

8. Jabbari B, Huott AD (1980) Seizures in thyrotoxicosis. Epilepsia 21: 91-96.

9. Daher R, Yazbeck T, Jaoude JB, Abboud B (2009) Consequences of dysthyroidism on the digestive tract and viscera. World $\mathrm{J}$ Gastroenterol 15: 2834-2838.

10. Klieverik LP, Kalsbeek A, Ackermans $M T$, Sauerwein HP, Wiersinga WM, et al. (1996) $\beta$-Cell function and glucose and lipid oxidation in Graves' disease. J Clin Endocrinol Metab 44: 59-66.

11. Klein I, Ojamaa K (2000) The cardiovascular system in hypothyroidism. In: Werner and Ingbar's (eds.) The Thyroid: a fundamental and clinical text (8th edn.) J B Lippincott Co., Philadelphia, pp: 777-782.

12. Udayakumar N, Rameshkumar AC, Srinivasan AV (2005) Hoffmann syndrome: presentation in hypothyroidism. J Postgrad Med 51: 332-333. 
13. Capasso G, De Santo NG, Kinne R (1987) Thyroid hormones and renal transport: cellular and biochemical aspects. Kidney Int 32: 443-451.

14. van Hoek I, Daminet S (2009) Interactions between thyroid and kidney function in pathological conditions of these organ systems: a review. Gen Comp Endocrinol 160: 205-215.
15. Axelrod AR, Berman $L$ (1951) The bone marrow in hyperthyroidism and hypothyroidism. Blood 6: 436-53.

16. http://www.homeorizon.com/homeopathy-printouts/ endocrinology/homeopathic-perspective-on-thyroid-disorders 